\title{
Assessing the climate trade-offs of gasoline direct injection engines
}

\author{
Naomi Zimmerman, Jonathan M. Wang, Cheol-Heon Jeong, \\ James S. Wallace, and Greg J. Evans
}

Version Post-print/accepted manuscript

Citation Zimmerman, N., Wang, J. M., Jeong, C. H., Wallace, J. S., \& Evans, G. (published version) J. (2016). Assessing the climate trade-offs of gasoline direct injection engines. Environmental Science \& Technology, 50(15), 8385-8392.

Publisher's Statement This document is the Accepted Manuscript version of a Published Work that appeared in final form in Environmental Science and Technology, copyright (C) American Chemical Society after peer review and technical editing by the publisher. To access the final edited and published work see 10.1021/acs.est.6b01800.

\section{How to cite TSpace items}

Always cite the published version, so the author(s) will receive recognition through services that track citation counts, e.g. Scopus. If you need to cite the page number of the author manuscript from TSpace because you cannot access the published version, then cite the TSpace version in addition to the published version using the permanent URI (handle) found on the record page.

This article was made openly accessible by $U$ of 'T Faculty. Please tell us how this access benefits you. Your story matters. 


\section{Assessing the climate trade-offs of gasoline direct}

\section{2 injection engines}

3

4

5

6

8

10

11

12

13

14

15

16

17

18

19

20

21

22

23

Naomi Zimmerman, ${ }^{\dagger},{ }^{*}, x$ Jonathan M. Wang, ${ }^{\dagger}$ Cheol-Heon Jeong, ${ }^{\dagger}$ James S. Wallace, ${ }^{+}$Greg J.

Evans $^{\dagger}$

†Department of Chemical Engineering and Applied Chemistry, University of Toronto, Toronto,

Ontario M5S3E5 Canada

$\$$ Department of Mechanical and Industrial Engineering, University of Toronto, Toronto, Ontario

M5S3G8 Canada

*Corresponding author:

Dr. Naomi Zimmerman

Dept. of Chemical Engineering and Applied Chemistry

University of Toronto

200 College Street, Toronto, Canada, M5S 3E5

xPresent address:

Dept. of Mechanical Engineering

Carnegie Mellon University

5000 Forbes Avenue, Pittsburgh, PA 15213

Tel. 412-268-2490

Fax. 416-978-8605

Email: naomi.zimmerman @ mail.utoronto.ca 


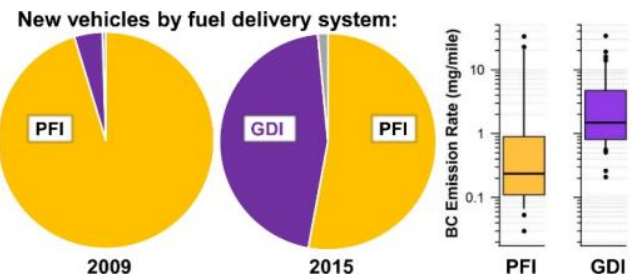

28 Compared to port fuel injection (PFI) engine exhaust, gasoline direct injection (GDI) engine exhaust has higher emission of black carbon (BC), a climate-warming pollutant. However, the relative increase in BC emissions and climate trade-offs of replacing PFI vehicles with more fuel

31 efficient GDI vehicles remain uncertain. In this study, BC emissions from GDI and PFI vehicles were compiled and BC emissions scenarios were developed to evaluate the climate impact of GDI vehicles using global warming potential (GWP) and global temperature potential (GTP) metrics.

34 From a 20-year time horizon GWP analysis, average fuel economy improvements ranging from 0.14-14\% with GDI vehicles are required to offset BC-induced warming. For all but the lowest $\mathrm{BC}$ scenario, installing a gasoline particulate filter with an $80 \% \mathrm{BC}$ removal efficiency and $<1 \%$ fuel penalty is climate beneficial. From the GTP-based analysis, it was also determined that GDI vehicles are climate beneficial within <1-20 years; longer time horizons were associated with higher BC scenarios. The GDI BC emissions spanned two orders of magnitude and varied by ambient temperature, engine operation, and fuel composition. More work is needed to understand

$41 \mathrm{BC}$ formation mechanisms in GDI engines to ensure that the climate impacts of this engine 42 technology are minimal. 


\section{INTRODUCTION}

44 In 2013, emissions from light-duty vehicles accounted for approximately $16 \%$ of the total greenhouse gas emissions in the United States, amounting to slightly more than one billion metric tons of $\mathrm{CO}_{2}$-equivalents ${ }^{1}$. Beginning in 2011, the United States Corporate Average Fuel Economy (CAFE) standards were tightened to reduce $\mathrm{CO}_{2}$ emissions from fuel combustion. It is predicted that by 2017 , fleet-average fuel economy will exceed $38 \mathrm{mpg}$ and will continue to increase by $5 \%$ per year until 2025, at which point minimum fuel economy must reach $55 \mathrm{mpg}^{2,3}$. In recent years, the spark ignition gasoline direct injection (GDI) engine, an alternative to the traditional port fuel injection (PFI) engine, has gained popularity as means of meeting these CAFE standards while simultaneously increasing specific power ${ }^{4}$, especially when coupled with turbocharging ${ }^{5}$. These engines can also be designed to operate with higher biofuel blends (up to 85\% ethanol) to further reduce $\mathrm{CO}_{2}$ emissions. GDI-equipped vehicles are being rapidly integrated into the vehicle fleet; in the United States, between model years 2009 and 2015 the percentage of new vehicles with GDI engines increased from $<5 \%$ to $46 \%^{6}$, and it is projected that in 2020 GDI-equipped vehicles will represent over $50 \%$ of the on-road vehicle fleet ${ }^{7,8}$. However, the main trade off of replacing PFI engines with GDI engines is a substantial increase in exhaust particulate matter (PM) emissions ${ }^{9-}$ ${ }^{12}$, a problem previously associated with diesel fuel combustion. A significant fraction of the GDI exhaust $\mathrm{PM}_{2.5}$ is black carbon (BC), a pollutant with large positive radiative forcing due to its ability to absorb incoming sunlight and reduce surface albedo on snow ${ }^{13}$. Previous studies have reported the fraction of elemental carbon (considered here to be analogous to BC) in the GDI exhaust $\mathrm{PM}_{2.5}$ to range from $2-29 \%{ }^{14}$ with elemental to organic carbon (EC/OC) ratios for GDI engine exhaust PM ranging from 0.5-20 12,15,16. Compared to PFI engines, which currently make up the bulk of the North American vehicle fleet, similar BC-to- $\mathrm{PM}_{2.5}$ ratios have been observed ${ }^{17}$; 
however, GDI engine exhaust contains higher total concentrations of BC ${ }^{17-21}$. For example, realworld BC emissions from a 2013 GDI were in the $73^{\text {rd }}$ percentile of the Toronto fleet ${ }^{21}$.

GDI engine exhaust PM is primarily formed due to incomplete fuel volatilization causing fuel impingement on cylinder and piston surfaces, and incomplete fuel mixing with air resulting in pockets of fuel-rich combustion. The extent of fuel-air mixing can be further affected by injection system design. There are two major classes of injection systems for GDI engines: spray-guided and wall-guided, which differ in where the fuel is injected into the cylinder, the piston head design, and the fuel injection strategy. For spray-guided systems (Figure 1A), some of the fuel is directed towards the spark plug for ignition, while the remaining fuel is dispersed into the remainder of the cylinder. Wall-guided systems (Figure 1B) primarily rely on piston head geometry for fuel-air mixing; the fuel spray is injected near the wall towards the piston head where it is redirected towards the spark plug for ignition. Less fuel-air mixing time is available with GDI engines compared to PFI engines, in which fuel mixes with the air intake upstream of the exhaust cylinder (Figure 1C). Commercially available GDI vehicles have been mostly equipped with wall-guided systems; however, there has been some movement towards spray-guided systems in lieu of wallguided systems due to their potential to reduce the number of particles emitted ${ }^{22-24}$ and black carbon ${ }^{25}$, likely due to improved fuel-air mixing with the spray-guided design.

Given that GDI vehicles will generally reduce $\mathrm{CO}_{2}$ emissions per vehicle distance travelled while simultaneously increasing BC emissions, an assessment of the climate trade-off is needed to ensure that integration of GDI vehicles will result in a net reduction of $\mathrm{CO}_{2}$-equivalent emissions. In this study, $\mathrm{BC}$ emission rates (ERs) from our previous study ${ }^{21}$ and from the literature were compiled. From these emission rates, BC emissions scenarios were constructed to determine the fuel economy improvements needed to offset the increase in black carbon using both global 
warming potential (GWP) and global temperature potential (GTP) metrics. Briefly, GWP and GTP are metrics for calculating the climate forcing from a unit mass emission of a species relative to the climate forcing from an equivalent mass emission of $\mathrm{CO}_{2}$. The GWP is a measure of the radiative forcing integrated over a given time horizon, while the GTP is an end-point metric of the temperature change at the end of a given time horizon. The development, equations, and uncertainties associated with these metrics in the context of $\mathrm{BC}$ are discussed in detail elsewhere ${ }^{13,26-28}$ and summarized in the Supporting Information. Additionally, a trade-off assessment of gasoline particulate filter fuel penalty and BC reduction efficiency is discussed. Four emissions scenarios were chosen to represent the broad range of reported BC emissions, which were reported across variable ambient temperatures, vehicle operation, and fuel compositions.

\section{METHODS}

\subsection{Black carbon emission rates}

In addition to the black carbon emission factors from Zimmerman et al. ${ }^{21}$, emission rates (mg $\mathrm{BC} / \mathrm{mile})$ were compiled from the published literature ${ }^{17-21,25,29,30}$. Only emissions from North American commercially available vehicles were considered. In Zimmerman et al. ${ }^{21}$, fuel-based BC emission factors were originally reported ( $\mathrm{mg} \mathrm{BC} / \mathrm{kg}$ fuel burned). To convert to distance-based emission rates, real-time fuel economy data from an on-board diagnostics logger (OBD-II, ELM327) was used. For all other studies, BC emissions were originally reported on a distancetravelled basis. In most of the published studies, specific vehicle fuel economies and the relationship between fuel economy and vehicle operation were unreported.

A summary of the distance-based BC emission factors (emission rates, $\mathrm{mg} / \mathrm{mile}$ ) for GDI and PFI vehicles is provided in Figure 2, sorted by vehicle model year (MY). All available BC emission factors were included independent of engine operation, measurement environment 
(laboratory, real-world), temperature and relative humidity. However, only emissions from vehicles fuelled with $10 \%$ ethanol or less were included ${ }^{17-21,25,29,30}$. The effect of fuel properties on $\mathrm{BC}$ emissions is considered separately in the discussion.

Figure 2 shows individual reported $\mathrm{BC}$ emission rates along with box-whisker averaging of the BC emission rates for PFI and wall-guided GDI engines. Due to the paucity of published data on spray-guided GDI engine emissions, this engine type was excluded from the averaging and subsequent analysis. A detailed list of the individual studies used to develop Figure 2 as well as pertinent experimental details are provided in the Supporting Information.

\subsection{Climate trade-off analysis: GWP and GTP}

To quantify the climate impact of the fuel economy/black carbon trade-off, four BC emission scenarios were developed using the data from Figure 2 representative of the range of $\mathrm{BC}$ emissions reported (Table 1). To address the uncertainty in the difference between GDI and PFI BC emissions, a Monte Carlo sampling procedure was employed ${ }^{31}$. A similar analysis approach has been used to quantify uncertainty in forest fire emissions ${ }^{32,33}$, air toxics emissions ${ }^{34}$ and global black carbon inventories ${ }^{35}$. Briefly, one GDI and one PFI BC emission rate was selected randomly and the difference was computed. This was repeated 100,000 times to generate a distribution of solutions. From this distribution we generated four emissions scenarios: scenario A ("mean $\Delta \mathrm{BC}$ "), the average $\triangle \mathrm{BC}$ from the Monte Carlo analysis, scenario B ("low $\Delta \mathrm{BC}$ "), the $25^{\text {th }}$ percentile of the Monte Carlo distribution, scenario $C$ ("high $\triangle B C$ "), the $75^{\text {th }}$ percentile of distribution, and scenario D ("extreme $\triangle \mathrm{BC}$ "), the $95^{\text {th }}$ percentile of the distribution. The four $\mathrm{BC}$ emission rate scenarios were then converted into $\mathrm{CO}_{2}$-equivalent emissions using global warming potential (GWP) data for a 20-year time horizon ${ }^{13}$. Subsequently, the required percent fuel economy improvement to offset the black carbon emissions was calculated by comparing the increase in 
$\mathrm{CO}_{2}$-equivalent emissions from $\mathrm{BC}\left(\mathrm{CO}_{2} \mathrm{~g}\right.$-eq/mile $)$ to the reduction in $\mathrm{CO}_{2}$ emissions by reducing fuel consumption by a given percentage. Here, the baseline fuel economy was assumed to be 21.4 miles per gallon, the average fuel economy of the in-use United States light-duty fleet in $2014^{36}$. $\mathrm{A} \mathrm{CO}_{2}$ emission factor was calculated assuming a fuel carbon content of $8887 \mathrm{~g} / \mathrm{gallon}^{6}$. Details of this assessment illustrated with a sample calculation are provided in the Supporting Information.

The GWP provides the radiative forcing due to a pulse emission integrated over the time horizon and use of this metric to compare short-lived (BC) and long-lived $\left(\mathrm{CO}_{2}\right)$ species may significantly overestimate the impact of the short-lived species ${ }^{28}$ (see Supporting Information for an expanded discussion of this effect). To further explore the trade-off, an analysis was also conducted using the global temperature potential (GTP) metric. In contrast, the GTP is an endpoint metric that provides the global mean temperature change for a given year after the emissions and thus does not reflect the higher time-integrated-based impact of short-lived species, such as $\mathrm{BC}$, in the preceding years. A detailed discussion of the advantages and drawbacks of the GWP and GTP metrics is analyzed in detail elsewhere ${ }^{13,37}$ and is also summarized in the Supporting Information for completeness. Additionally, many GWP and GTP analyses assume a pulse emission at the beginning of the time horizon vs. a sustained emission over a specified period. For example, in the case of a new car purchasing scenario (i.e., buying a GDI in lieu of a PFI vehicle), an appropriate sustained emission period might be 10-15 years, roughly the average lifetime of a new vehicle ${ }^{28,38}$. Thus, to determine a more conservative estimate of the climate trade-offs of GDI engines, the GTP-based analysis assumed a 10 year sustained emission period based on available data $^{28}$. The underlying assumption here is that the $\mathrm{BC}$ emissions will drop back down for the subsequent car purchased due to improved vehicle technologies. 
they define a parameter $\mathrm{X}$ to assess whether a trade-off situation is beneficial or detrimental to

climate (Eq. 1), where $\triangle \mathrm{BC}$ is the net increase in $\mathrm{BC}$ emissions from purchasing a GDI vehicle instead of a PFI vehicle (from Table 1) and $\Delta \mathrm{CO}_{2}$ is the reduction in $\mathrm{CO}_{2}$ emissions by improving fuel economy with GDI.

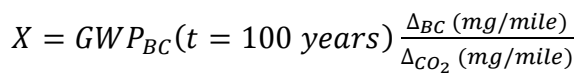

Boucher and Reddy ${ }^{28}$ also demonstrate that the critical value of $\mathrm{X}$ at a given time horizon $t$ is inversely proportional to the GTP of "normalized" BC $\left(\mathrm{GTP}_{\mathrm{nBC}}, \mathrm{Eq} .2\right)$. As defined by Boucher and Reddy ${ }^{28}$, normalized $\mathrm{BC}(\mathrm{nBC})$ is a hypothetical BC-like short-lived species that has the same lifetime as $\mathrm{BC}$, but the same 100 -year absolute $\mathrm{GWP}$ as $\mathrm{CO}_{2}$ (i.e., 100 year $\mathrm{GWP}_{\mathrm{nBC}}=1$ ).

$$
X_{\text {limit }}(t)=\frac{1}{\operatorname{GTP}_{n B C}(t)}
$$

As the parameter $\mathrm{X}$ as defined in equation (1) is based on the 100 year GWP of BC, it follows that the critical value of X is inversely proportional to the GTP of the hypothetical "normalized" BC, which has the same 100 year GWP as $\mathrm{CO}_{2}$. Using the $\mathrm{GTP}_{\mathrm{nBC}}$ values from Figures 4 and 6 in Boucher and Reddy ${ }^{28}$ for a 10 year sustained release period, Eq. (1) and Eq. (2) were equated and the critical required improvement in fuel economy was calculated for Scenarios A through D (Table 1) for time horizons ranging from 1-40 years. A sample calculation is provided in the Supporting Information.

\section{RESULTS AND DISCUSSION}

\subsection{Global warming potential (GWP)}

Figure 3 illustrates the trade-off analysis of BC emissions and fuel economy for scenarios A through D. The fuel economy gain needed to offset BC-induced warming is represented as the 
intercept with the $\mathrm{x}$-axis (net zero $\mathrm{CO}_{2}$-equivalent emissions). The average fuel economy gains needed to offset the $\mathrm{BC}$ emissions ranged from $0.14 \%$ for the low $\triangle \mathrm{BC}$ emissions scenario (B) to $14 \%$ for the extreme $\triangle \mathrm{BC}$ scenario (D). The bounded regions in Figure 3 represent the reported uncertainty associated with the BC GWP. Incorporating this uncertainty into the estimate, the required fuel economy gains to offset the $\mathrm{BC}$-induced warming range from $0.04 \%$ (negligible) for the low $\triangle \mathrm{BC}$ emissions scenario (B) to $26 \%$ for the extreme $\triangle \mathrm{BC}$ scenario (D).

To determine the expected fuel economy improvements from purchasing a GDI vehicle, we utilized data from Appendix I of the annual United States Environmental Protection Agency (US EPA) report on fuel economy data from 1975 to 2015 (Table 2) ${ }^{6}$, which provides average fuel economy data by model year and engine type. The fuel economies reported in Table 2 are "adjusted" fuel economies, which are the US EPA's estimate of real-world fuel economy performance. Here, we consider two case studies: one in which an in-use PFI-equipped vehicle is replaced with a new GDI-equipped vehicle (Case 1A,1B), and another in which a consumer buys a new GDI-equipped vehicle in lieu of a new PFI-equipped vehicle (Case 2). In the replacement cases (Case 1A, 1B), replacing a 2005 model year PFI-engine-equipped vehicle with a 2015 GDI vehicle, unsurprisingly, results in large fuel economy gains ranging from 9-14\%. However, when comparing the fuel economy gains from replacing a fleet-standard PFI vehicle 5 years newer, the impact is less substantial. Choosing to replace a 2010 PFI-engine-equipped vehicle with a 2015 GDI vehicle only results in fuel economy improvements of up to $4 \%$ for highway driving and negligible changes for city and combined driving. In a new car purchase scenario (Case 2), the average 2015 model year PFI-engine-equipped vehicle is more fuel efficient than a 2015 GDI vehicle by margins ranging from $7-12 \%$. This is possibly due to the fact that GDI-equipped 
vehicles have higher brake specific fuel consumption than their PFI counterparts ${ }^{6}$ (i.e., a GDI vehicle likely has a more powerful engine than a PFI vehicle with equivalent fuel economy).

On a 20-year timescale, we estimate from our GWP-based calculation (Figure 3) that replacing older PFI-equipped vehicles, such as a fleet-average 2005 PFI vehicle, with a new fuel efficient GDI-equipped vehicle (Case 1A) should result in a net climate benefit across all scenarios. The climate impacts of choosing to replace a 2010 PFI-equipped vehicle with a new GDI vehicle are less clear based on this analysis, as we found that replacing 2010 PFI vehicles should only reduce $\mathrm{CO}_{2}$-equivalent emissions for scenarios $\mathrm{A}$ through $\mathrm{C}$. When considering a new car purchase (Case 2), given that fleet-average 2015 model year PFI vehicles achieve comparable or better fuel economy than GDI vehicles, purchasing the PFI vehicle will always result in lower $\mathrm{CO}_{2}$-equivalent emissions due to the added value of the avoided black carbon. While we only discuss fleet-averages in this simple assessment, our analysis highlights the need to carefully compare the fuel economy-black carbon trade-off when evaluating impact of a vehicle on climate.

\subsection{Global Temperature Potential (GTP) Analysis}

Figure 4 shows the GTP-based trade-off analysis of BC emissions and fuel economy for scenarios A through D. This assessment assumed a sustained release period of 10 years (roughly the lifetime of a single vehicle) using GTP values published in Boucher and Reddy ${ }^{28}$ (data is re-created in the Supporting Information). For time horizons ranging from 1 through 40 years, the minimum improvement in fuel economy required to offset the increase $\mathrm{BC}$ emissions (by equating equations (1) and (2) and solving for $\Delta \mathrm{CO}_{2}$, repeating for $\mathrm{n}=1,2, \ldots 40$ years) was calculated. An example of this calculation is provided in the Supporting Information. As an example of the realistic fuel economy gains with GDI engine technology, the estimated fuel economy improvements achieved 
by replacing a fleet-average 2005 (Case 1A) and 2010 PFI vehicle (Case 1B) with a 2015 GDI vehicle (see Table 2, combined fuel economy) are overlaid on Figure 4.

For all scenarios in this example, the climate benefit has some dependence on the considered time horizon, which is defined here as the time beginning from the point of vehicle purchase. For scenario A (mean $\triangle \mathrm{BC}$ ), replacing an older PFI vehicle with a GDI vehicle is only climate-detrimental for 2 (Case 1A) to 17 years (Case 1B) after vehicle purchase, beyond which the increase in BC is offset by the overall reduction in fuel consumption. Similarly, the time horizon beyond which the replacement becomes climate beneficial ranges from $<1$ year (Case 1A) to 4 years (Case 1B) for scenario B (low $\Delta \mathrm{BC}$ ), from 7.5 (Case 1A) to 24 years (Case 1B) for scenario $\mathrm{C}($ high $\triangle \mathrm{BC}$ ), and 18 (Case $1 \mathrm{~A})$ to 40 years (Case $1 \mathrm{~B})$ for scenario $\mathrm{D}$ (extreme $\Delta \mathrm{BC}$ ). Given the lower probability of the "extreme $\triangle \mathrm{BC}$ " scenario, we suggest that for time horizons exceeding 20 years, replacement of 2010 or earlier PFI vehicles with more fuel efficient GDI vehicles will eventually start yielding climate benefits 20 years after purchase. Further, greater climate benefits will eventually occur if the GDI vehicle is operated for longer than the 10-year vehicle lifetime used in this analysis. However, for a new car purchase decision (Table 2, Case 2), choosing a PFI-vehicle is recommended to minimize overall climate impacts.

\subsection{Impact of gasoline particulate filters (GPFs)}

Many studies have investigated the installation of gasoline particulate filters (GPFs) to reduce BC and total particle emissions from GDI vehicles ${ }^{20,39-43}$. Particulate filters have been very effective at reducing PM and BC emissions from diesel vehicles; however, developing effective GPFs may require overcoming several technical challenges. GDI-equipped vehicles emit less exhaust PM than diesel vehicles, resulting in a situation where GPFs may initially have a very low filtration efficiency due to the longer time needed to build up a soot layer within the filter ${ }^{41}$. Gasoline engine 
exhaust is also approximately $300{ }^{\circ} \mathrm{C}$ hotter than diesel exhaust, and these higher temperatures may favour more frequent passive regeneration events, limiting the buildup of PM in the filter ${ }^{44}$. Commercial installation of diesel particulate filters, which have a similar operating principle as GPFs, has typically resulted in fuel penalties in the range of $2-3 \%{ }^{45,46}$. In contrast, several studies have found that GPFs can be installed without compromising overall vehicle fuel economy ${ }^{39,43,47-49}$, in which case installation of a GPF is always climate beneficial and may also offer significant health benefits by the reduction of ultrafine particles and $\mathrm{PM}_{2.5}$. However, a recent study by Chan et al. ${ }^{44}$ observed a $1.9 \%$ reduction in fuel economy during an aggressive highway driving cycle (US06), possibly due to high exhaust flow rates during aggressive driving conditions. If GPF installation results in a similar fuel penalty to those of diesel particulate filters, this may offset the climate benefits of reducing the $\mathrm{BC}$ emissions. This is explored in Figure 5, using the same BC emission scenarios (Table 1) and the 20-year average GWP. Fuel penalties ranging from 0.5\%-3\% were considered and the critical GPF filtration efficiency for net zero $\mathrm{CO}_{2}$-equivalent emissions was calculated. Details of the calculation are provided in the Supporting Information.

On a 20-year time horizon the critical GPF BC removal efficiency to offset the increase in $\mathrm{CO}_{2}$ from a fuel penalty varies significantly by $\mathrm{BC}$ emissions scenario. For scenario A (mean $\triangle \mathrm{BC})$, the reduction in $\mathrm{BC}$ emissions will not compensate for the fuel penalty if this penalty exceeds $1 \%$ (i.e., installing a GPF is not climate beneficial). For $0.5 \%$ and $1 \%$ fuel penalties, GPF BC removal efficiency must exceed $40 \%$ and $80 \%$, respectively. For scenario $\mathrm{B}$ (low $\Delta \mathrm{BC}$ ), the $\mathrm{CO}_{2}$ emissions incurred from a small $0.5 \%$ fuel penalty would not offset the removal of $\mathrm{BC}$ (i.e., $\mathrm{BC}$ emissions are too low to warrant GPF installation if fuel economy is compromised). For scenarios $\mathrm{C}$ (high $\triangle \mathrm{BC}$ ) and $\mathrm{D}$ (extreme $\triangle \mathrm{BC}$ ), installing a GPF with $\mathrm{BC}$ filtration efficiency of at least $60 \%$ should offset the $\mathrm{CO}_{2}$ increase for the fuel penalties equal to or less than $2 \%$. Chan et 
271 al. ${ }_{4}^{50}$. have reported BC removal efficiencies with a GPF ranging from $57 \%\left(-7{ }^{\circ} \mathrm{C}\right.$, US-06 drive

272 cycle) to $89 \%\left(-7{ }^{\circ} \mathrm{C}\right.$, FTP-75 drive cycle), suggesting this level of removal is achievable.

\footnotetext{
Conversely, manufacturers striving to reduce the climate impact of vehicles may find inclusion of
} a GPF as a more easily achievable opportunity than reducing fuel efficiency by an additional 0.5$3 \%$. For example, if a GPF can be developed without a fuel penalty as suggested in the early literature $39,43,47-49$, then installation of GPFs might offset part of the 2025 requirements for improved fuel efficiency. As such, continued GPF research with a focus on minimizing fuel penalty is recommended. Given the potential technical challenges of commercial GPF design, engineering strategies to reduce $\mathrm{BC}$ in absence of a GPF is also desirable, such as a reduction in BC by moving towards spray-guided direct injection technology.

\subsection{Fuel properties and GDI BC emissions}

The GDI BC emissions in Figure 2 span approximately two orders of magnitude, suggesting that $\mathrm{BC}$ emissions are dependent on external factors such as fuel composition. The most investigated fuel property when considering particle phase GDI engine emissions is the effect of ethanol and other biofuels. Ethanol blending in gasoline has been largely motivated by perceived reductions in greenhouse gas emissions when ethanol is produced from renewable sources. If ethanol could be used to formulate new fuels with higher octane numbers, significant reductions of $\mathrm{CO}_{2}$ emissions could be achieved ${ }^{51}$. However, ethanol is currently blended into gasoline stocks to achieve only fuels with standard octane numbers $(87,89$, and 91 anti knock index). Additionally, the impact of ethanol on PM emissions from GDI vehicles is highly variable and there is no general consensus on its impact. While many studies report universal PM (and by extension BC) reductions from biofuel use ${ }^{11,12,15,52}$, others report both increases and decreases in PM emissions depending on engine operation or blend level ${ }^{16,29,53-56}$. Furthermore, the range of benefit is large and inconsistent 
across the same blend levels from different studies. Part of the variability may be explained by fuel injection spray effects. A recent study of fuel effects on the spray wall impingement in an optically accessible wall guided GDI engine that found that spray wall impingement of E100 (pure ethanol) was less sensitive to coolant temperature than pure indolene fuel ${ }^{57}$. Also, the normalized vaporization duration was shorter for E100 compared to E0 (indolene). The inconsistent effects of ethanol addition require greater investigation when considering that replacing gasoline with ethanol has been shown previously to result in a net decrease in lifecycle greenhouse gas emissions 58

As an example, in Zimmerman et al. ${ }^{21}$, it was observed that increasing the ethanol content of gasoline from 0 to $10 \%$ (on a volumetric basis) resulted in a $114 \%$ increase in elemental carbon (EC) concentration (considered here to be equivalent to BC) during a simulated highway cruise operation. Using the laboratory EC emission factors reported in Zimmerman et al. ${ }^{21}(45 \mathrm{mg} / \mathrm{kg}$ fuel for E0, $95 \mathrm{mg} / \mathrm{kg}$ fuel for E10), the 20 and 100 year GWPs of BC from Bond et al. ${ }^{13}$, and an overall $19 \%$ reduction in life-cycle greenhouse gases from replacing gasoline with ethanol ${ }^{58}$, the net climate impact of ethanol can be roughly assessed. Details of this calculation are provided in the Supporting Information. In this example it was determined that on average, the $114 \%$ increase in EC measured in Zimmerman et al. ${ }^{21}$ should offset the greenhouse gas benefits of ethanol on a 20-year time horizon, but not on a 100-year time horizon (Supporting Information, Figure S1). However, this is only one example, and further assessments are needed make more conclusive statements on the climate impacts of GDI vehicles using ethanol-blended fuels.

The effect of ethanol on GDI BC engine emissions may also be convoluted by the impacts of other fuel properties, such as aromatic content and blending technique (i.e., splash vs. match blending). In Karavalakis et al. ${ }^{30}$, fuel aromatic content was systematically increased from $15 \%$ to 
$31735 \%$ and the impact on PN, PM and black carbon emissions was measured. They found that that increasing fuel aromatics from $15 \%$ to $35 \%$ resulted in a $395 \%$ increase in PM, a $266 \%$ increase in PN, and a 154\% increase in black carbon, suggesting that aromatic compounds are precursors for soot formation. Ramos ${ }^{16}$ also observed that doping commercially-available E0 gasoline with $10 \%$ toluene, a common fuel aromatic, resulted in approximately $70 \%$ higher particle number emissions, and when doping E10 with $10 \%$ toluene, particle number emissions further increased by $64 \%$, potentially suggesting a synergistic effect that is not currently understood. Differences in blending techniques between studies may also influence results, as "splash" blended fuels may have different hydrocarbon profiles and vapor pressures than fuels produced using match blending ${ }^{59}$.

In California, regulations on reformulated gasoline mandate a maximum aromatics content of $25 \%$ by volume; no such regulation exists federally in the United States or in Canada. Of the studies used to compile the $\mathrm{BC}$ emission scenarios, over half were conducted in California, thus our scenarios would be disproportionately influenced by data reported from this state, where fuel aromatics are lower. In contrast, a commercially-available summer-blend premium 91 octane fuel sample in Toronto, Canada contained $43 \%$ aromatics by volume (fuel analysis in Supporting Information). The $\mathrm{BC}$ emissions data from two separate Canadian studies were roughly an order of magnitude higher than those from California studies, suggesting that understanding the impact of fuel properties on $\mathrm{BC}$ emissions, which may vary significantly by region, is critical to developing a more precise climate trade-off analysis of GDI engine emissions. 
From this study, it was determined that a broad range of fuel economy improvements $(0.04 \%$ to $26 \%$ ) with GDI vehicles are required to offset the BC-induced warming. This large range was primarily due to the large uncertainty in the impacts of GDI engines on BC emissions. From the more complex GTP-based analysis with a sustained emission release scenario of 10 years, it was determined that replacing a fleet-average pre-2010 PFI vehicle with a fleet-average GDI vehicle will generally offer climate benefits within 20 years of putting the vehicle into use. As such, detrimental climate impacts due to the integration of the current generation GDI vehicles into the fleet will likely still be observed over the near-term, especially for new car purchase scenarios, where PFI vehicles outperform GDI vehicles on the basis of fuel economy and BC emissions.

Generally, installing a gasoline particulate filter with a $<1 \%$ fuel penalty would result in a net climate benefit for filtration efficiencies exceeding $80 \%$. However, if $\mathrm{BC}$ emissions are sufficiently small (scenario B) then installation of a GPF is never advantageous to climate if there is any associated fuel penalty. However, given that preliminary implementations of GPFs suggest that negligible fuel penalties are possible, we suggest a more holistic regulatory approach that also considers a reduction in $\mathrm{BC}$ as an offset to the demands for greater fuel efficiency by 2025 . Furthermore, if GPFs can be implemented with a negligible fuel penalty, there may be considerable co-benefits to human health by a reduction in vehicle exhaust PM. This could also be achieved through modifications to GDI engine design that promote less PM and BC formation.

The climate trade-off analysis conducted in this study lacked precision due to the broad range of reported $\mathrm{BC}$ emissions from GDI vehicles, combined with the uncertainty of the GWP and GTP metrics. In this study we were also limited to data from integrated drive cycles and we 
were not able to isolate the impacts from specific vehicle operation. Additionally, one study suggests higher BC emissions under cold temperatures ${ }^{39}$, but we did not model this specific effect due to limited data. We also were unable to account for the cooling effects of organic aerosol emissions due to a lack of available data. Future studies that include the effects of organic carbon cooling, that focus on cold temperature data or on $\mathrm{BC}$ emissions during specific vehicle operation where fuel economies are reported would greatly enhance our understanding of the climate tradeoffs of GDI engines.

Of greatest significance to $\mathrm{BC}$ emissions were fuel properties, in particular total aromatic content, which may vary substantially by geographic area. As such, it is recommended that additional GDI emissions studies in regions where total fuel aromatics are high, or studies of a broader range of fuel types are needed to better understand the potential range of BC emissions. Additionally, more studies of the impacts of spray-guided or advanced GDI engines on BC emissions are needed to verify if this engine technology results in lower $\mathrm{BC}$ emissions than the wall-guided GDI design. In this study, the BC emissions data from spray-guided GDI engines were too limited to develop an emissions scenario. It is expected that as spray-guided injectors are increasingly used in GDI engines or as GDI engine technology develops, BC and PM emissions may be significantly reduced. As such, it is recommended that these metrics be revisited when more data is available from engines with advanced injection strategies.

\section{ACKNOWLEDGEMENTS}

Funding for this study was provided by the Canada Foundation for Innovation (CFI 19606) and the Natural Sciences and Engineering Research Council (NSERC) Strategic Project Grant program (STPGP 396488-10). N. Zimmerman's funding was provided by the NSERC Postgraduate Scholarship. 


\section{SUPPORTING INFORMATION}

A tabulated list of black carbon emission factors included in the scenarios, a discussion of the global warming potential (GWP) and global temperature potential (GTP) metrics, sample calculations for the climate trade-off assessments, and a fuel sample analysis of summer-grade commercial fuel from Toronto, Canada is provided.

\section{REFERENCES}

(1) United States Environmental Protection Agency. Inventory of U.S. Greenhouse Gas Emissions and Sinks: 1990-2013; 2015.

(2) United States Department of Transportation. Final regulatory impact analysis, corporate average fuel economy for MY 2012-MY 2016 passenger cars and light trucks; Washington, D.C., 2010.

(3) United States Environmental Protection Agency. 2017 and later model year light-duty vehicle greenhouse gas emissions and corporate average fuel economy standards; final rule. Fed. Regist. 2012, 77 (199), 62624-63200.

(4) Zhao, F.; Lai, M. C.; Harrington, D. L. Automotive spark-ignited direct-injection gasoline engines. Prog. Energy Combust. Sci. 1999, 25 (5), 437-562.

(5) Lecointe, B.; Monnier, G. Downsizing a Gasoline Engine Using Turbocharging with Direct Injection. In SAE Technical Papers; 2003.

(6) United States Environmental Protection Agency. Light-Duty Automotive Technology, Carbon Dioxide Emissions, and Fuel Economy Trends: 1975 Through 2015; 2015.

(7) United States Environmental Protection Agency. Final rulemaking to establish light-duty vehicle greenhouse gas emission standards and corporate average fuel economy standards; 2010.

(8) Kassel, R.; Couch, P.; Connolly, M.; Hammer-Barulich, A. Ultrafine particulate matter and the benefits of reducing particle numbers in the United States: A report to the Manufacturers of Emission Controls Association; 2013.

(9) Graham, L. Chemical characterization of emissions from advanced technology light-duty vehicles. Atmos. Environ. 2005, 39 (13), 2385-2398.

(10) Khalek, I. A.; Bougher, T.; Jetter, J. J. Particle emissions from a 2009 gasoline direct injection engine using different commercially available fuels. SAE Int. J. Fuels Lubr. 2010, 3 (2), 623-637.

(11) Liang, B.; Ge, Y.; Tan, J.; Han, X.; Gao, L.; Hao, L.; Ye, W.; Dai, P. Comparison of PM emissions from a gasoline direct injected (GDI) vehicle and a port fuel injected (PFI) vehicle measured by electrical low pressure impactor (ELPI) with two fuels: Gasoline and M15 methanol gasoline. J. Aerosol Sci. 2013, 57, 22-31. 
(12) Maricq, M. M.; Szente, J. J.; Jahr, K. The impact of ethanol fuel blends on PM emissions from a light-duty GDI vehicle. Aerosol Sci. Technol. 2012, 46 (5), 576-583.

(13) Bond, T. C.; Doherty, S. J.; Fahey, D. W.; Forster, P. M.; Berntsen, T.; DeAngelo, B. J.; Flanner, M. G.; Ghan, S.; Kärcher, B.; Koch, D.; et al. Bounding the role of black carbon in the climate system: A scientific assessment. J. Geophys. Res. Atmos. 2013, 118 (11), 5380-5552.

(14) Price, P.; Stone, R.; OudeNijeweme, D.; Chen, X. Cold Start Particulate Emissions from a Second Generation DI Gasoline Engine. In SAE Technical Paper 2007-01-1931; 2007.

(15) Storey, J. M.; Barone, T.; Norman, K.; Lewis, S. Ethanol Blend Effects On Direct Injection Spark-Ignition Gasoline Vehicle Particulate Matter Emissions. SAE Int. J. Fuels Lubr. 2010, 3 (2), 650-659.

(16) Ramos, M. Sources of Particulate Matter Emissions Variability from a Gasoline Direct Injection Engine, University of Toronto, 2014.

(17) Short, D. Z.; Vu, D.; Durbin, T. D.; Karavalakis, G.; Asa-Awuku, A. Components of Particle Emissions from Light-Duty Spark-Ignition Vehicles with Varying Aromatic Content and Octane Rating in Gasoline. Environ. Sci. Technol. 2015.

(18) Forestieri, S. D.; Collier, S.; Kuwayama, T.; Zhang, Q.; Kleeman, M. J.; Cappa, C. D. Real-time black carbon emission factor measurements from light duty vehicles. Environ. Sci. Technol. 2013, 47 (22), 13104-13112.

(19) Kamboures, M. A.; Hu, S.; Yu, Y.; Zhang, S.; Ling, R.; Sandoval, J.; Dzhema, I.; Huo, D.; Rieger, P. A baseline assessment and comparison of particulate matter and black carbon emissions from gasoline direct injection vehicles. In Air and Waste Management Association - Symposium on Air Quality Measurement Methods and Technology 2010; 2010; Vol. 2, pp 942-946.

(20) Chan, T. W.; Meloche, E.; Kubsh, J.; Brezny, R. Black carbon emissions in gasoline exhaust and a reduction alternative with a gasoline particulate filter. Environ. Sci. Technol. 2014, 48 (10), 6027-6034.

(21) Zimmerman, N.; Wang, J. M.; Jeong, C.-H.; Ramos, M.; Hilker, N.; Healy, R. M.; Sabaliauskas, K.; Wallace, J. S.; Evans, G. Field measurements of gasoline direct injection emission factors: spatial and seasonal variability. Environ. Sci. Technol. 2016, 50 (4), 2035-2043.

(22) Price, P.; Stone, R.; Collier, T.; Davies, M. Particulate Matter and Hydrocarbon Emissions Measurements: Comparing First and Second Generation DISI with PFI in Single Cylinder Optical Engines. In SAE Technical Papers; 2006.

(23) Choi, K.; Kim, J.; Myung, C.-L.; Lee, M.; Kwon, S.; Lee, Y.; Park, S. Effect of the mixture preparation on the nanoparticle characteristics of gasoline direct-injection vehicles. Proc. Inst. Mech. Eng. Part D J. Automob. Eng. 2012, 226 (11), 1514-1524.

(24) Zhang, S.; McMahon, W. Particulate Emissions for LEV II Light-Duty Gasoline Direct Injection Vehicles. SAE Int. J. Fuels Lubr. 2012, 5 (2), 637-646.

(25) Bahreini, R.; Xue, J.; Johnson, K.; Durbin, T.; Quiros, D.; Hu, S.; Huai, T.; Ayala, A.; 
Jung, H. Characterizing emissions and optical properties of particulate matter from PFI and GDI light-duty gasoline vehicles. J. Aerosol Sci. 2015, 90, 144-153.

(26) Fuglestvedt, J. S.; Shine, K. P.; Berntsen, T.; Cook, J.; Lee, D. S.; Stenke, a.; Skeie, R. B.; Velders, G. J. M.; Waitz, I. a. Transport impacts on atmosphere and climate: Metrics. Atmos. Environ. 2010, 44 (37), 4648-4677.

(27) Bond, T. C.; Zarzycki, C.; Flanner, M. G.; Koch, D. M. Quantifying immediate radiative forcing by black carbon and organic matter with the Specific Forcing Pulse. Atmos. Chem. Phys. 2011, 11 (4), 1505-1525.

(28) Boucher, O.; Reddy, M. S. Climate trade-off between black carbon and carbon dioxide emissions. Energy Policy 2008, 36 (1), 193-200.

(29) Karavalakis, G.; Short, D.; Vu, D.; Villela, M.; Asa-Awuku, A.; Durbin, T. D. Evaluating the regulated emissions, air toxics, ultrafine particles, and black carbon from SI-PFI and SI-DI vehicles operating on different ethanol and iso-butanol blends. Fuel 2014, 128, $410-421$.

(30) Karavalakis, G.; Short, D. Z.; Vu, D.; Russell, R. L.; Hajbabaei, M.; Asa-Awuku, A.; Durbin, T. D. Evaluating the effects of aromatics content in gasoline on gaseous and particulate matter emissions from SI-PFI and SI-DI vehicles. Environ. Sci. Technol. 2015, 49 (11), 7021-7031.

(31) Cullen, A. C.; Frey, H. C. Probabilistic Techniques in Exposure Assessment: A Handbook for dealing with variability and uncertainty in models and inputs; Plenum Press: New York, 1999.

(32) Werf, G. R. Van Der; Randerson, J. T.; Giglio, L.; Collatz, G. J.; Mu, M.; Kasibhatla, P. S.; Morton, D. C. Global fire emissions and the contribution of deforestation, savanna, forest, agricultural, and peat fires. Atmos. Chem. Phys. 2010, 10, 11707-11735.

(33) French, N. H. F.; Goovaerts, P.; Kasischke, E. S. Uncertainty in estimating carbon emissions from boreal forest fires. J. Geophys. Res. 2004, 109 (D14S08), 1-12.

(34) Zhao, Y.; Frey, H. C. Development of Probabilistic Emission Inventories of Air Toxics for Jacksonville, Florida. J. Air Waste Manage. Assoc. 2004, 54, 1405-1421.

(35) Bond, T. C.; Streets, D. G.; Yarber, K. F.; Nelson, S. M.; Woo, J.; Klimont, Z. A technology-based global inventory of black and organic carbon emissions from combustion. J. Geophys. Res. 2004, 109 (D14203), 1-43.

(36) United States Department of Transportation. Table 4-23: Average Fuel Efficiency of U.S. Light Duty Vehicles | Bureau of Transportation Statistics http://www.rita.dot.gov/bts/sites/rita.dot.gov.bts/files/publications/national_transportation _statistics/html/table_04_23.html.

(37) Stohl, A.; Aamaas, B.; Amann, M.; Baker, L. H.; Bellouin, N.; Berntsen, T. K.; Boucher, O.; Cherian, R.; Collins, W.; Daskalakis, N.; et al. Evaluating the climate and air quality impacts of short-lived pollutants. Atmos. Chem. Phys. Discuss. 2015, 15 (11), 1515515241.

(38) Tanaka, K.; Berntsen, T.; Fuglestvedt, J. S.; Rypdal, K. Climate Effects of Emission 
Standards: The Case for Gasoline and Diesel Cars. Environ. Sci. Technol. 2012, 46, 52055213.

(39) Chan, T. W.; Meloche, E.; Kubsh, J.; Brezny, R.; Rosenblatt, D.; Rideout, G. Impact of Ambient Temperature on Gaseous and Particle Emissions from a Direct Injection Gasoline Vehicle and its Implications on Particle Filtration. SAE Int. J. Fuels Lubr. 2013, $6(2)$.

(40) Mamakos, A.; Martini, G.; Marotta, A.; Manfredi, U. Assessment of different technical options in reducing particle emissions from gasoline direct injection vehicles. J. Aerosol Sci. 2013, 63, 115-125.

(41) Saito, C.; Nakatani, T.; Miyairi, Y.; Yuuki, K.; Makino, M.; Kurachi, H.; Heuss, W.; Kuki, T.; Furuta, Y.; Kattouah, P.; et al. New Particulate Filter Concept to Reduce Particle Number Emissions. In SAE 2011 World Congress and Exhibition; 2011.

(42) Seo, J.; Lee, J. S.; Choi, K. H.; Kim, H. Y.; Yoon, S. S. Numerical investigation of the combustion characteristics and wall impingement with dependence on split-injection strategies from a gasoline direct-injection spark ignition engine. Proc. Inst. Mech. Eng. Part D J. Automob. Eng. 2013, 227 (11), 1518-1535.

(43) Spiess, S.; Wong, K. F.; Richter, J. M.; Klingmann, R. Investigations of emission control systems for gasoline direct injection engines with a focus on removal of particulate emissions. Top. Catal. 2013, 56 (1-8), 434-439.

(44) Chan, T. W.; Saffaripour, M.; Liu, F.; Hendren, J.; Thomson, K. A.; Kubsh, J.; Brezny, R.; Rideout, G. Characterization of Real-Time Particle Emissions from a Gasoline Direct Injection Vehicle Equipped with a Catalyzed Gasoline Particulate Filter During Filter Regeneration. Emiss. Control Sci. Technol. 2016, 1-14.

(45) Letavec, C.; Uihlein, J.; Hallstrom, K.; Vertin, K.; Chandler, K.; Coburn, T.; Wayne, S.; Clark, N.; Gautam, M.; Thompson, G.; et al. Year-Long Evaluation of Trucks and Buses Equipped with Passive Diesel Particulate Filters. SAE Tech. Pap. Ser. 2002, 2002-01-04.

(46) Lev-on, M.; Letavec, C.; Uihlein, J.; Alleman, T. L.; Lawson, D. R.; Vertin, K.; Thompson, G. J.; Gautam, M.; Wayne, S.; Zielinska, B.; et al. Chemical Speciation of Exhaust Emissions from Trucks and Buses Fueled on Ultra-Low Sulfur Diesel and CNG. SAE Tech. Pap. Ser. 2002, 2002-01-04.

(47) Choi, K.; Kim, J.; Ko, A.; Myung, C.-L.; Park, S.; Lee, J. Size-resolved engine exhaust aerosol characteristics in a metal foam particulate filter for GDI light-duty vehicle. $J$. Aerosol Sci. 2013, 57, 1-13.

(48) Lambert, C. K.; Bumbaroska, M.; Dobson, D.; Hangas, J.; Pakko, J.; Tennison, P. Analysis of High Mileage Gasoline Exhaust Particle Filters. SAE Int. J. Engines 2016, 9 (2).

(49) Richter, J. M.; Klingmann, R.; Spiess, S.; Wong, K.-F. Application of Catalyzed Gasoline Particulate Filters to GDI Vehicles. SAE Int. J. Engines 2012, 5 (3), 1361-1370.

(50) Chan, T. W.; Meloche, E.; Kubsh, J.; Brezny, R. Black carbon emissions in gasoline exhaust and a reduction alternative with a gasoline particulate filter. Environ. Sci. Technol. 
2014, 48 (10), 6027-6034.

(51) Anderson, J. E.; DiCicco, D. M.; Ginder, J. M.; Kramer, U.; Leone, T. G.; Raney-Pablo, H. E.; Wallington, T. J. High octane number ethanol-gasoline blends: Quantifying the potential benefits in the United States. Fuel 2012, 97, 585-594.

(52) Chen, L.; Braisher, M.; Crossley, A.; Stone, R.; Richardson, D. The Influence of Ethanol Blends on Particulate Matter Emissions from Gasoline Direct Injection Engines. In $S A E$ Technical Papers; 2010.

(53) He, X.; Ratcliff, M. A.; Zigler, B. T. Effects of gasoline direct injection engine operating parameters on particle number emissions. Energy \& Fuels 2012, 26 (4), 2014-2027.

(54) Chen, L.; Stone, R.; Richardson, D. Effect of the valve timing and the coolant temperature on particulate emissions from a gasoline direct-injection engine fuelled with gasoline and with a gasoline-ethanol blend. Proc. Inst. Mech. Eng. Part D J. Automob. Eng. 2012, 226 (10), 1419-1430.

(55) Chan, T. W.; Meloche, E.; Kubsh, J.; Rosenblatt, D.; Brezny, R.; Rideout, G. Evaluation of a Gasoline Particulate Filter to Reduce Particle Emissions from a Gasoline Direct Injection Vehicle. SAE Int. J. Fuels Lubr. 2012, 5 (3), 1277-1290.

(56) Wang, C.; Xu, H.; Herreros, J. M.; Wang, J.; Cracknell, R. Impact of fuel and injection system on particle emissions from a GDI engine. Appl. Energy 2014, 132, 178-191.

(57) Fatouraie, M.; Wooldridge, M. S.; Petersen, B. R.; Wooldridge, S. T. Spray Development and Wall Impingement of Ethanol and Gasoline in an Optical Direct Injection Spark Ignition Engine. In Volume 1: Large Bore Engines; Fuels; Advanced Combustion; ASME, 2015; p V001T02A004.

(58) Wang, M.; Wu, M.; Huo, H. Life-cycle energy and greenhouse gas emission impacts of different corn ethanol plant types. Environ. Res. Lett. 2007, 2 (2), 024001.

(59) Schifter, I.; Diaz, L.; Rodriguez, R.; Gómez, J. P.; Gonzalez, U. Combustion and emissions behavior for ethanol - gasoline blends in a single cylinder engine. Fuel 2011, 90 (12), 3586-3592. 

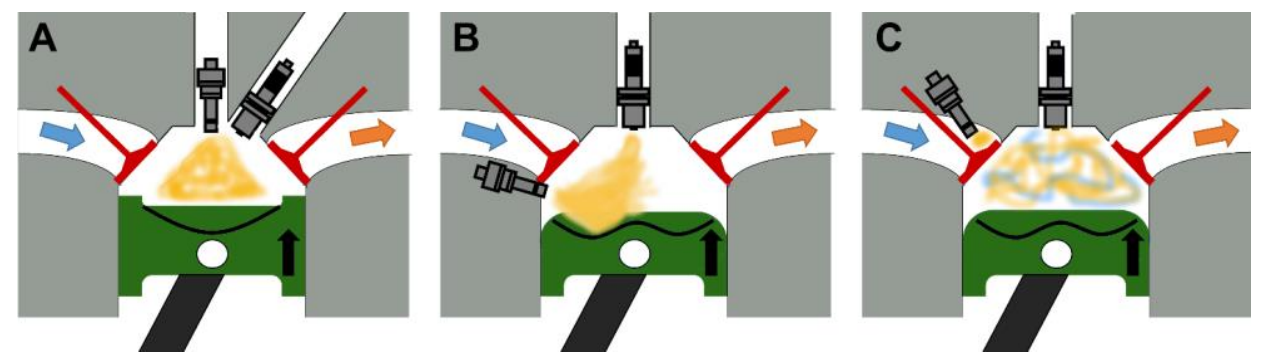

Figure 1: Injection systems for A) spray-guided and B) wall-guided GDI engines (adapted from Zhao et al. ${ }^{4}$ compared to C) the injection system for a typical PFI engine where fuel is injected into the air intake manifold. Blue arrow: air intake, orange arrow: exhaust outflow.
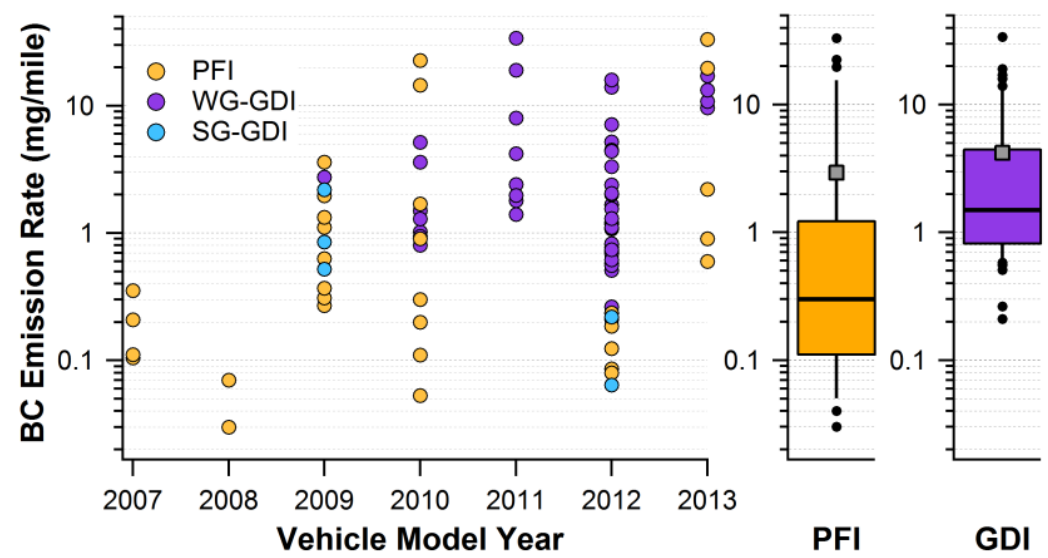

Figure 2: Summary of literature reported black carbon (BC) emission rates for 2007-2013 model year vehicles with port fuel injection (PFI, yellow), wall-guided gasoline direct injection (WG-GDI, purple), and spray-guided gasoline direct injection (SG-GDI, blue) engines (left) and a box-whisker plot of PFI and WG-GDI emission rates. The line is the median value, the gray marker is the arithmetic mean, the box ends are the $25^{\text {th }}$ and $75^{\text {th }}$ quartiles, whiskers extend to the $10^{\text {th }}$ and $90^{\text {th }}$ percentiles, and outliers are denoted as markers beyond the whiskers. 

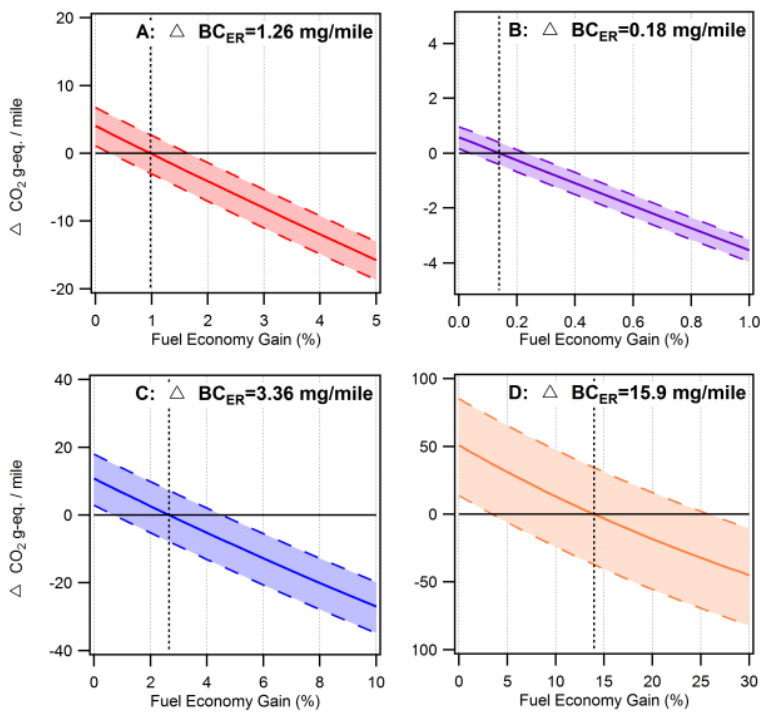

Figure 3: Climate trade-off analysis of increased black carbon emissions vs. improved fuel economy on a 20-year time horizon. Labels A, B, C, and D correspond to the emissions scenarios described in Table 1. Dashed lines represent upper and lower GWP uncertainty bounds from Bond et al. ${ }^{13}$ (Average GWP $=3200$, Lower $=270$, Upper $=6200$ ). The fuel economy gain needed to offset $\mathrm{BC}$-induced warming is represented as the intercept with the $\mathrm{x}$-axis (net zero $\mathrm{CO}_{2}$-equivalent emissions)

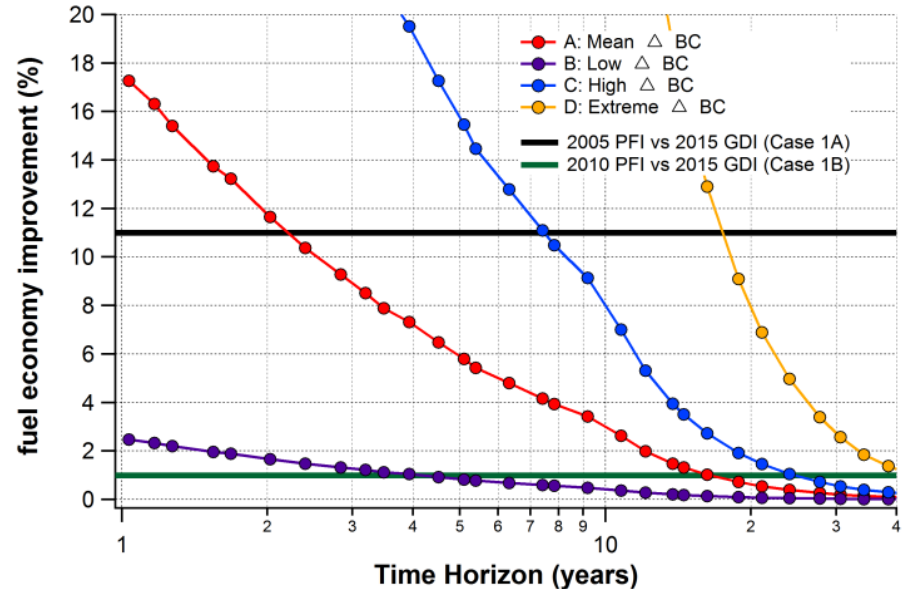

Figure 4: Required fuel economy improvement to offset the increase in $\mathrm{BC}$ emissions for scenarios $\mathrm{A}$ (mean, red bars), B (low BC, purple bars), C (high BC, blue bars) and D (extreme BC, gold bars) (see Table 1 for emission scenario details). Gray and green lines: fuel economy improvements ("Adjusted Combined") by replacing a fleetaverage 2005 (gray) and 2010 (green) PFI vehicle with a GDI vehicle. 


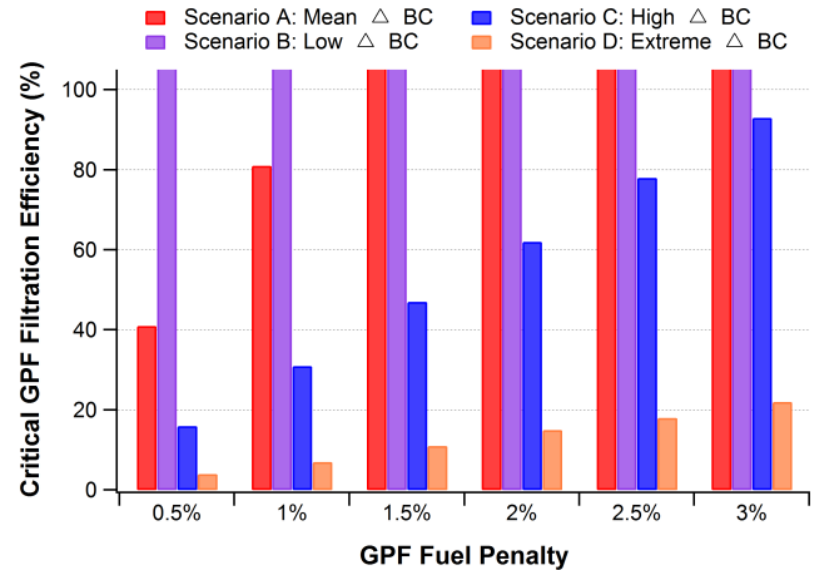

Figure 5: Required $\mathrm{BC}$ removal efficiency for a GPF to offset fuel penalties ranging from $0.5-3 \%$ for emission scenarios A (mean, red bars), B (low BC, purple bars), C (high BC, blue bars) and D (extreme BC, gold bars) (see Table 1 for emission scenario details. Analysis uses 20-year average GWP from Bond et al. ${ }^{13}$ (Average 20-year GWP $=3200$ ). 
Table 1: Black carbon emission rate (ER) scenarios developed from the data in Figure 2. Scenarios were developed using a Monte Carlo method $(n=100,000)$ in which we randomly selected one WG-GDI ER and one PFI ER and calculated the difference ( $\left.\triangle \mathrm{BC} E \mathrm{ER}=\mathrm{WG}-\mathrm{GDI}_{\mathrm{ER}}-\mathrm{PFI}_{\mathrm{ER}}\right)$.

\begin{tabular}{lll}
\hline Scenario & $\begin{array}{l}\Delta \mathbf{B C} \text { ER } \\
(\mathbf{m g} / \mathbf{m i l e})\end{array}$ & Description \\
\hline A: Mean & 1.26 & $\begin{array}{l}\text { Mean } \Delta \mathrm{BC} \text { emissions from the Monte Carlo } \\
\text { analysis }\end{array}$ \\
\hline B: Low BC & 0.18 & $\begin{array}{l}25^{\text {th }} \text { percentile of } \Delta \mathrm{BC} \text { emissions from the Monte } \\
\text { Carlo analysis }\end{array}$ \\
\hline C: High BC & 3.36 & $\begin{array}{l}75^{\text {th }} \text { percentile of } \Delta \mathrm{BC} \text { emissions from the Monte } \\
\text { Carlo analysis }\end{array}$ \\
\hline D: Extreme & 15.9 & $\begin{array}{l}95^{\text {th }} \text { percentile of } \Delta \mathrm{BC} \text { emissions from the Monte } \\
\text { Carlo analysis }\end{array}$ \\
\hline
\end{tabular}

603

604

605

606

607

608

Table 2: Average adjusted (Adj) city, highway (Hwy), and combined (Comb) fuel economy in miles per gallon (MPG) for the U.S. 2005, 2010, and 2015 PFI vehicle fleet and 2015 GDI vehicle fleet $^{6}$. All values are for vehicles with variable valve timing and multi-valve systems. The relative change in fuel economy for different vehicles is also summarized.

\begin{tabular}{|c|c|c|c|c|c|c|}
\hline 2005 & 2010 & 2015 & 2015 & Case 1: & Case 2A: & Case 2B: \\
\hline $\begin{array}{l}\text { PFI } \\
\text { (PFI-1) }\end{array}$ & $\begin{array}{l}\text { PFI } \\
\text { (PFI-2) }\end{array}$ & $\begin{array}{l}\text { PFI } \\
\text { (PFI-3) }\end{array}$ & GDI & $\begin{array}{l}\% \text { change, } \\
\text { replace PFI-1 } \\
\text { with GDI }\end{array}$ & $\begin{array}{l}\% \text { change, buy } \\
\text { GDI instead of } \\
\text { PFI-2 }\end{array}$ & $\begin{array}{l}\% \text { change, buy } \\
\text { GDI instead of } \\
\text { PFI-3 }\end{array}$ \\
\hline
\end{tabular}

\begin{tabular}{lccccccc}
\hline $\begin{array}{l}\text { Adj City } \\
\text { (MPG) }\end{array}$ & 20.7 & 22.9 & 25.8 & 22.6 & $\mathbf{+ 9 \%}$ & $\mathbf{- 1 \%}$ & $\mathbf{- 1 2 \%}$ \\
$\begin{array}{l}\text { Adj Hwy } \\
\text { (MPG) }\end{array}$ & 28.7 & 31.2 & 35.3 & 32.6 & $\mathbf{+ 1 4 \%}$ & $\mathbf{+ 4 \%}$ & $\mathbf{- 7 \%}$ \\
$\begin{array}{l}\text { Adj Comb } \\
\text { (MPG) }\end{array}$ & 24.6 & 27.0 & 30.4 & 27.4 & $\mathbf{+ 1 1 \%}$ & $\mathbf{+ 1 \%}$ & $\mathbf{- 1 0 \%}$ \\
\hline
\end{tabular}

